\title{
Penerapan Model Pembelajaran Think, Pair, Share untuk Meningkatkan Keterampilan Berwawancara Siswa SD
}

\author{
Friska Ayu Lia Yulanda $^{1}$, Heri Suwignyo ${ }^{2}$, Supriyono Koeshandayanto ${ }^{3}$ \\ ${ }^{1}$ Pendidikan Dasar-Universitas Negeri Malang \\ ${ }^{2}$ Pendidikan Bahasa dan Sastra Indonesia-Universitas Negeri Malang \\ ${ }^{3}$ Pendidikan Fisika-Universitas Negeri Malang
}

\begin{tabular}{l} 
INFO ARTIKEL \\
\hline Riwayat Artikel: \\
Diterima: $18-07-2019$ \\
Disetujui: $15-01-2020$ \\
\hline
\end{tabular}

\section{Kata kunci:}

learning model;

think, pair, share;

interviewing skill;

model pembelajran ;

think, pair, share;

keterampilan berwawancara

\begin{abstract}
ABSTRAK
Abstract: This study aims to describe the improvement of interviewing skill by Think, Pair, Share learning model in fourth grade students of SDN Dukuharum Jombang. This Classroom Action Research consists of 2 cycles which is each cycle consisting of 4 meetings. The subjects of this study were 15 fourth grade students of SDN Dukuharum Jombang. The analysis technique uses descriptive analysis. Data were collected by observation, interview and documentation. Through this study, the students improvement of interviewing skills in the first cycle achieve $70.5 \%$ in average and the second cycle is $77.2 \%$ in average. The results prove that Think, Pair, Share learning model can improve the student's interviewing skill.

Abstrak: Penelitian ini bermanfaat untuk mengetahui peningkatan keterampilan berwawancara dengan menggunakan model pembelajaran Think, Pair, Share pada siswa kelas IV SDN Dukuharum Jombang. Jenis penelitian ini adalah PTK yang terdiri dari dua siklus dengan rincian tiap siklus terdiri dari empat pertemuan. Subjek penelitian ini adalah siswa kelas IV SDN Dukuharum Jombang. Teknik analisis menggunakan analisis deskriptif. Pengumpulan data menggunakan observasi, wawancara, dokumentasi. Hasil penelitian ini terdapat peningkatan keterampilan berwawancara siswa rata-rata pada siklus I sebesar $70,5 \%$ pada siklus II mencapai 77,2\%. Dengan demikian, hasil penelitian ini menunjukkan bahwa melalui model pembelajaran Think, Pair, Share dapat meningkatkan keterampilan berwawancara siswa.
\end{abstract}

\author{
Alamat Korespondensi: \\ Friska Ayu Lia Yulanda \\ Pendidikan Dasar \\ Universitas Negeri Malang \\ Jalan Semarang 5 Malang \\ E-mail: yulandaliaayufriska@gmail.com
}

Keterampilan berbahasa di Sekolah Dasar, meliputi kegiatan menyimak, menulis, membaca, dan berbicara (Mudiono, 2010). Kemampuan berbicara digunakan untuk menyampaikan informasi yang diperoleh secara lisan dan memiliki kaidah tertentu dengan memperhatikan beberapa aspek (Tarigan, 2008). Salah satu pembelajaran keterampilan berbicara di SD kelas IV sesuai dengan kurikulum 2013 adalah keterampilan berwawancara. Kegiatan mendapatkan informasi melalui kegiatan tanya jawab dengan narasumber yang memperhatikan intonasi dan lafal disebut wawancara (Mudini dan Salamat, 2009). Untuk dapat memiliki keterampilan berwawancara baik dibutuhkan penguasaan aspek lafal, intonasi, kalimat tanya yang akan diajukan kepada narasumber. Namun, hal ini tidak sejalan dengan kenyataan yang ada di lapangan bahwa siswa masih kesulitan untuk menguasai keterampilan berwawancara dengan baik. Kesulitan menguasai keterampilan berwawancara yang baik sejalan dengan penelitian yang dilakukan oleh (Erawan, 2014) yang menyatakan berwawancara merupakan keterampilan yang dianggap sulit oleh $80 \%$ siswa. Berdasarkan pengamatan yang dilakukan di SDN Dukuharum kepada siswa kelas IV pada tanggal 3 September 2018 mengenai keterampilan berwawancara ditemukan hasil bahwa dalam pembelajaran berwawancara masih rendah. Hal tersebut ditunjukkan dengan 12 dari 15 siswa hasil wawancara tentang peduli terhadap makhluk hidup masih dibawah KKM hanya tiga siswa tuntas KKM.

Permasalahan yang muncul saat pembelajaran keterampilan berwawancara siswa tidak percaya diri, saat mengajukan pertanyaan berbicara tidak lancar, suaranya terdengar tidak jelas, pandangan mata tidak fokus ke narasumber justru menunduk, intonasi kurang tepat, diksi kurang tepat. Selain itu, ditemukan juga sepuluh siswa yang tidak mengetahui apa yang akan ditanyakan karena kesulitan membuat daftar pertanyaan yang sesui dengan topik. Dua siswa merasa kebingungan dan meminta kepada guru untuk diberikan contoh. Namun, siswa lebih banyak menggunakan pertanyaan sama hampir $80 \%$ dari contoh yang diberikan. 
Peneliti juga menemukan permasalahan khususnya dalam mengembangkan keterampilan berwawancara siswa, yaitu siswa hanya berfokus pada pencapaian materi belum memperhatikan aspek non kebahasaan. Selain itu, kegiatan belajar mengajar kurang efektif, siswa berwawancara dengan temannya dan tidak mendapatkan umpan balik dari guru. Serta belum adanya model pembelajaran sesuai untuk mendukung kegiatan berwawancara siswa. Proses pembelajaran sebaiknya memberikan pengalaman langsung untuk mempermudah siswa dalam berwawancara. Siswa dapat percaya diri dan berani ketika melakukan kegiatan berwawancara dengan narasumber. Terdapat model pembelajaran yang mendukung siswa percaya diri dan berani serta mampu membuat pertanyaan dengan baik dan benar adalah menggunakan model pembelajaran Think, Pair, Share. Model Think Pair Share merupakan model pembelajaran yang dapat memicu siswa untuk bekerjasama dengan orang lain dan memberikan waktu untuk berpikir sendiri menyelesaikan tugas serta mengemukakan gagasan (Sampsel, 2013); (Williams, 2011).

Hal tersebut didukung oleh penelitian yang dilakukan oleh (Kusuma \& Aisyah, 2012) menyatakan bahwa model pembelajaran Think, Pair, Share mampu mengajukan pertanyaan, mengamati materi yang dijelaskan oleh guru atau kelompok, serta mampu mengerjakan tugas secara mandiri. Selain itu, (Rosita \& Leonard, 2015); (Raba, 2017) kepedulian terhadap kesulitan sesama anggota kelompok serta dapat meningkatkan kerjasama antar siswa. (Sugiarto \& Sumarsono, 2014); (Usman, 2015) juga menyatakan kalau model pembelajaran Think, Pair, Share mampu membuat siswa aktif dan kreatif. Berdasarkan paparan tersebut peneliti terdorong untuk melakukan suatu penelitian tindakan kelas sebagai usaha perbaikan kualitas proses dan kualitas hasil pembelajaran keterampilan berwawancara dengan judul "Peningkatan Keterampilan Berwawancara dengan menggunakan Model Pembelajaran Think, Pair, Share pada siswa kelas IV SDN Dukuharum Jombang Tahun Pembelajaran 2018/2019".

\section{METODE}

Penelitian ini menggunakan penelitian tindakan kelas yang bertujuan untuk mengatasi masalah yang ada di kelas dan meningkatkan kualitas belajar siswa. Peran peneliti sebagai pengamat, mencari data, menganalisis data dan pengambil keputusan (Mulyasa, 2013). Penelitian ini bertempat di SDN Dukuharum Jalan Raya Dukuharum No. 65, Desa Dukuharum, Kecamatan Megaluh, Kabupaten Jombang. Penelitian ini bersifat kolaborasi antara guru dan peneliti. Subjek penelitian yaitu siswa kelas IV SDN Dukuharum Jombang sebanyak 15 siswa. Objek penelitian yang diambil berupa proses pembelajaran menggunakan model pembelajaran Think, Pair, Share dan hasil keterampilan berwawancara. Teknik pengumpulan data berupa pengamatan, wawancara, dokumentasi, catatan lapangan, dan tes. Teknik analisis data dengan cara reduksi data, penyajian data, dan penarikan kesimpulan (Miles \& Huberman, 2010).

\section{HASIL}

Data keterampilan berwawancara siswa kelas IV SDN Dukuharum Jombang diperoleh dari hasil pengamatan saat pembelajaran dan hasil berwawancara siswa pada siklus I dan II (Tabel 1). Semua siswa mendapatkan nilai di atas KKM yaitu sebanyak 15 siswa. Didukung juga dengan data rerata nilai keterampilan berwawancara siswa setiap aspek pada siklus I dan II (Tabel 2).

Tabel 1. Peningkatan Keterampilan Berwawancara Siswa Siklus I dan II

\begin{tabular}{|c|c|c|c|c|c|c|c|c|c|c|c|c|}
\hline No & Nama & NP 1 & NP 2 & Rata-rata (\%) & Kriteria & Ket & NP 3 & NP 4 & $\sum$ & Rata-rata (\%) & Kriteria & Keterangan \\
\hline 1 & Assa & 71 & 71 & 71 & Baik & $\mathrm{T}$ & 77 & 82 & 159 & 79,5 & Baik & $\mathrm{T}$ \\
\hline 2 & Awan & 69 & 71 & 70 & Baik & $\mathrm{T}$ & 74 & 77 & 151 & 75,5 & Baik & $\mathrm{T}$ \\
\hline 3 & Brian & 71 & 77 & 74 & Baik & $\mathrm{T}$ & 80 & 82 & 162 & 81 & Sangat Baik & $\mathrm{T}$ \\
\hline 4 & Vyco & 69 & 71 & 70 & Baik & $\mathrm{T}$ & 74 & 74 & 148 & 74 & Baik & $\mathrm{T}$ \\
\hline 5 & Dinar & 69 & 74 & 71,5 & Baik & $\mathrm{T}$ & 77 & 80 & 157 & 78,5 & Baik & $\mathrm{T}$ \\
\hline 6 & Keyla & 66 & 69 & 67,5 & Baik & $\mathrm{TT}$ & 71 & 74 & 145 & 72,5 & Baik & $\mathrm{T}$ \\
\hline 7 & Ferdi & 63 & 69 & 66 & Baik & $\mathrm{TT}$ & 74 & 77 & 151 & 75,5 & Baik & $\mathrm{T}$ \\
\hline 8 & Nabila & 69 & 71 & 70 & Baik & $\mathrm{T}$ & 77 & 80 & 157 & 78,5 & Baik & $\mathrm{T}$ \\
\hline 9 & Nike & 69 & 74 & 71,5 & Baik & $\mathrm{T}$ & 77 & 80 & 157 & 78,5 & Baik & $\mathrm{T}$ \\
\hline 10 & Nonik & 71 & 71 & 71 & Baik & $\mathrm{T}$ & 74 & 77 & 151 & 75,5 & Baik & $\mathrm{T}$ \\
\hline 11 & Pandu & 71 & 74 & 72,5 & Baik & $\mathrm{T}$ & 77 & 80 & 157 & 78,5 & Baik & $\mathrm{T}$ \\
\hline 12 & Mitha & 69 & 71 & 70 & Baik & $\mathrm{T}$ & 74 & 77 & 151 & 75,5 & Baik & $\mathrm{T}$ \\
\hline 13 & Rendy & 71 & 74 & 72,5 & Baik & $\mathrm{T}$ & 77 & 80 & 157 & 78,5 & Baik & $\mathrm{T}$ \\
\hline 14 & Titis & 71 & 77 & 74 & Baik & $\mathrm{T}$ & 80 & 82 & 162 & 81 & Sangat Baik & $\mathrm{T}$ \\
\hline 15 & Gladys & 63 & 69 & 66 & Baik & TT & 71 & 74 & 145 & 72,5 & Baik & $\mathrm{T}$ \\
\hline \multicolumn{2}{|c|}{ Jumlah } & 1032 & 1083 & 1057,5 & & & 1134 & 1176 & 2310 & 1155 & & \\
\hline \multicolumn{2}{|c|}{ Rata-rata } & 68,8 & 72,2 & 70,5 & Baik & & 75,6 & 78,4 & 154 & 77,2 & Baik & \\
\hline
\end{tabular}


Tabel 2. Nilai Rata-Rata Keterampilan Siswa Setiap Aspek pada Siklus I dan II

\begin{tabular}{llcccccccc}
\hline & & \multicolumn{4}{c}{ Siklus I } & \multicolumn{4}{c}{ Siklus II } \\
\cline { 3 - 10 } No & \multirow{2}{*}{ Aspek } & $\mathbf{N P}$ & $\mathbf{N P}$ & $\boldsymbol{2}$ & Rata-rata & $\mathbf{N P}$ & $\mathbf{N P}$ & $\sum$ & \multirow{2}{*}{ Rata-rata } \\
\hline 1 & Intonasi & 2,6 & 3,3 & 5,9 & 2,95 & 3,6 & 3,8 & 7,4 & 3,7 \\
2 & Lafal & 2,5 & 3,3 & 5,8 & 2,9 & 3,5 & 3,7 & 7,2 & 3,6 \\
3 & Pemilihan Kata & 2,9 & 3,4 & 6,3 & 3,15 & 3,8 & 3,9 & 7,7 & 3,85 \\
4 & Kalimat Tanya & 2,2 & 3 & 5,2 & 2,6 & 3,8 & 4 & 7,8 & 3,9 \\
5 & Kelancaran & 2,8 & 3,3 & 6,1 & 3,05 & 3,8 & 4 & 7,8 & 3,9 \\
6 & Kesantunan & 3 & 3 & 6 & 3 & 3,8 & 3,9 & 7,7 & 3,85 \\
7 & Keberanian & 2,5 & 3,7 & 6,2 & 3,1 & 3,9 & 4 & 7,9 & 3,95 \\
\hline
\end{tabular}

Berdasarkan tabel 1 menunjukkan bahwa rerata hasil keterampilan berwawancara siswa pada siklus I dipersentasekan sebesar 70,5\% dari nilai pada penampilan pertama $68,8 \%$ dan penampilan kedua $72,2 \%$. Hasil tersebut belum mencapai target yang diharapkan dan nilai setiap aspek belum maksimal. Siswa yang mendapatkan nilai diatas 70 adalah 13 siswa dan siswa yang mendapatkan nilai dibawah 70 sebanyak tiga siswa. Rerata pada siklus II adalah $77,2 \%$ dengan kualifikasi baik dan sudah mencapai target yang diharapkan dari penampilan ketiga 75,6\% dan penampilan keempat 78,4\%.

Tabel 2. Nilai Rata-Rata Keterampilan Siswa Setiap Aspek pada Siklus I dan II

\begin{tabular}{|c|c|c|c|c|c|c|c|c|c|}
\hline \multirow[b]{2}{*}{ No } & \multirow[b]{2}{*}{ Aspek } & \multicolumn{4}{|c|}{ Siklus I } & \multicolumn{4}{|c|}{ Siklus II } \\
\hline & & $\begin{array}{c}\text { NP } \\
1\end{array}$ & $\begin{array}{c}\mathbf{N P} \\
\mathbf{2}\end{array}$ & $\sum$ & Rata-rata & $\begin{array}{c}\mathbf{N P} \\
\mathbf{3}\end{array}$ & $\begin{array}{c}\mathrm{NP} \\
\mathbf{4}\end{array}$ & $\sum$ & Rata-rata \\
\hline 1 & Intonasi & 2,6 & 3,3 & 5,9 & 2,95 & 3,6 & 3,8 & 7,4 & 3,7 \\
\hline 2 & Lafal & 2,5 & 3,3 & 5,8 & 2,9 & 3,5 & 3,7 & 7,2 & 3,6 \\
\hline 3 & Pemilihan Kata & 2,9 & 3,4 & 6,3 & 3,15 & 3,8 & 3,9 & 7,7 & 3,85 \\
\hline 4 & Kalimat Tanya & 2,2 & 3 & 5,2 & 2,6 & 3,8 & 4 & 7,8 & 3,9 \\
\hline 5 & Kelancaran & 2,8 & 3,3 & 6,1 & 3,05 & 3,8 & 4 & 7,8 & 3,9 \\
\hline 6 & Kesantunan & 3 & 3 & 6 & 3 & 3,8 & 3,9 & 7,7 & 3,85 \\
\hline 7 & Keberanian & 2,5 & 3,7 & 6,2 & 3,1 & 3,9 & 4 & 7,9 & 3,95 \\
\hline
\end{tabular}

Pada tabel 2 menunjukkan bahwa terjadi peningkatan pada rerata nilai keterampilan berwawancara. Hal tersebut didukung adanya perbaikan pada siklus II. Adapun kegiatan yang dilakukan pada proses pembelajaran berlangsung, yaitu (1) Siswa mendengarkan penjelasan kesalahan-kesalahan yang terdapat pada hasil keterampilan berwawancara pada siklus I dengan cara menampilkan hasil video wawancara siswa dengan petani pada siklus I; (2) guru menjelaskan materi tentang keterampilan berwawancara dari aspek kebahasaan dan non kebahasaan; (3) guru menerapkan model pembelajaran Think, Pair, Share pada tahap Think guru menampilkan video tata cara berwawancara yang baik untuk menstimulus siswa agar mampu berwawancara yang baik dengan memperhatikan intonasi, lafal, pemilihan kata, kalimat tanya, kelancaran, kesantunan dan keberanian; (4) Tahap Pair guru meminta siswa untuk berpasangan dengan temannya. Bermain peran dengan pasangannya melakukan kegiatan berwawancara sebagai pewawancara dan narasumber dengan memperhatikan kelancaran saat berbicara; (5) tahap Share guru meminta siswa untuk melakukan wawancara langsung dengan narasumber kepala desa disesuaikan dengan subtema II yaitu pemanfaatan sumber daya alam; (6) guru memberikan reward kepada siswa yang berani dan tidak malu kepada narasumber saat melakukan wawancara.

\section{PEMBAHASAN}

Kegiatan pembelajaran di kelas IV menggunakan model pembelajaran Think, Pair, Share dilaksanakan dua siklus, setiap siklus terdiri dari empat pertemuan. Pada pertemuan satu dan tiga penyampaian materi, sedangkan pertemuan kedua dan keempat siswa melaksanakan kegiatan berwawancara dengan narasumber petani dan kepala desa. proses pembelajaran dilaksanakan $3 \times 35$ menit pada setiap pertemuan. Dalam hal ini guru harus memperhitungkan alokasi waktu yang akan digunakan agar efisien.

Proses belajar mengajar siklus I pertemuan pertama dan ketiga dilaksanakan tiga tahap, yakni tahap think siswa membuat daftar pertanyaan untuk persiapan wawancara. Dalam membuat pertanyaan siswa mengalami kesulitan, guru menampilkan gambar kegiatan petani untuk menstimulus siswa. Gambar merupakan media yang mampu meningkatkan pemahaman dan motivasi siswa karena dapat memvisualisasi kegiatan yang belum pernah dilihat siswa (Tembang, Sulthon, Suharjo, 2017). Namun, pertemuan ketiga siswa mengamati video kegiatan petani karena hanya melalui gambar siswa masih kurang mendapatkan hasil yang maksimal. Setelah membuat pertanyaan tahap pair siswa berpasangan dengan temannya untuk saling memberikan masukan terhadap hasil kerjanya (Bamiro, 2015). Pada tahap ini siswa sangat antusias karena dapat memberikan masukan kepada pasangan. Tahap share siswa mempresentasikan hasil kerja bersama pasangan ke depan kelas. Siswa yang lain memperhatikan dan memberikan kritik serta saran. 
Pertemuan kedua dan keempat siswa juga melaksanakan dengan tahap think, pair, share. Hanya saja pada pertemuan ini tahap pair siswa berlatih bermain peran dengan pasangan memperagakan menjadi pewawancara dan narasumber dengan mengajukan pertanyaan yang sudah dibuat dan dikoreksi pada tahap think. Kegiatan bermain peran dapat meningkatkan keterampilan berwawancara siswa dari aspek non kebahasaan (Widyatirni, 2013). Selanjutnya, pada tahap share siswa melakukan wawancara langsung dengan narasumber petani. Rerata hasil keterampilan berwawancara penampilan pertama pada pertemuan kedua sebesar 68,8 \% terdapat 9 dari 15 siswa yang tidak tuntas KKM. Hal ini disebabkan siswa belum maksimal dalam aspek kebahasaan berupa intonasi, lafal, pemilihan kata dan kalimat tanya. Kemudian pada penampilan kedua pertemuan keempat mengalami peningkatan menjadi 72,2\% dan terdapat 3 dari 15 siswa yang belum tuntas KKM. Pada penampilan keempat ini siswa mengalami peningkatan karena pada pertemuan ketiga media pembelajaran yang awalnya gambar diganti menjadi video serta adanya waktu untuk berlatih berwawancara dengan temannya.

Selain itu, siswa juga mengalami peningkatan pada aspek keberanian pada penampilan pertama sebesar 2,3 menjadi 3,7 pada penampilan kedua hal ini berarti siswa sudah berani melakukan wawancara dengan berani dan percaya diri. Namun, berdasarkan hasil refleksi siswa sebaiknya diberikan contoh kegiatan tata cara berwawancara yang baik dan benar dengan memperhatikan aspek kebahasaan dan non kebahasaan karena hasil rerata nilai keterampilan berwawancara siswa masih belum maksimal yakni masih terdapat tiga siswa yang belum tuntas KKM dan aspek kesantunan, kelancaran belum maksimal. Kekurangan yang terjadi pada siklus I ini akan diperbaiki pada siklus II. Permasalahan yang terjadi pada siklus I akan diperbaiki pada siklus II. Siklus ini dilaksanakan empat kali pertemuan dengan rincian pertemuan pertama dan ketiga pembekalan materi, pertemuan dua dan empat pelaksanaan berwawancara dengan narasumber kepala desa.

Berdasarkan hasil refleksi pada siklus I maka pada siklus II pertemuan 1 tahap think siswa mengamati video reporter TV yang sedang mewawancarai narasumber. Siswa menganalisis video tersebut dengan memperhatikan intonasi, lafal, pemilihan kata, kalimat tanya, kelancaran, dan kesantunan. Setelah itu siswa menjawab pertanyaan guru tentang video tersebut yang mengarah pada aspek kebahasaan dan non kebahasaan. Hasil dari kegiatan tersebut siswa menemukan kalimat tanya yang digunakan belum lengkap yakni tidak ada kata mengapa. Dalam hal ini siswa sudah mampu menganalisis video yang ditampilkan harapannya siswa juga dapat menampilkan performa yang baik saat melakukan wawancara dengan kepala desa. Tahap pair guru memberikan waktu kepada siswa untuk berlatih dengan pasangan. Saat melakukan kegiatan berlatih siswa dapat memberikan penilaian kepada temannya untuk perbaikan penampilannya nanti (Deremisi \& Düzenli, 2017). Tahap share siswa melakukan wawancara langsung dengan kepala desa di kantor kelurahan. Hal ini membantu siswa untuk melatih Hasil wawancara siswa penampilan ketiga sebesar 75,6\% meningkat menjadi 78,4\% pada penampilan keempat. Peningkatan juga terjadi hampir pada semua aspek dengan rerata 3,7 intonasi, 3,6 lafal, 3,85 pemilihan kata, 3.9 kalimat tanya, 3,9 kelancaran, 3.85 kesantunan, 3,95 keberanian. Pada siklus II ini semua siswa sudah mendapatkan nilai di atas KKM. Hal ini disebabkan karena siswa diberi waktu untuk berlatih dan mendapatkan arahan serta bimbingan dari guru.

\section{SIMPULAN}

Rendahnya keterampilan berwawancara dapat ditingkatkan dengan menerapkan model pembelajaran Think, Pair, Share pada siswa kelas IV SDN Dukuharum Jombang. Adapun saran yang dapat diberikan adalah Pada tahap think guru sebaiknya menggunakan media pembelajaran yang bervariasi untuk menstimulus siswa agar mampu meningkatkan keterampilan membuat daftar pertanyaan yang bervariasi dan sesuai dengan tema. Pada tahap pair saat siswa berlatih berwawancara bersama pasangan guru sebaiknya memberikan waktu tersendiri di luar jam pelajaran untuk siswa berlatih agar siswa dapat lebih siap melakukan wawancara. Pada tahap share guru sebaiknya memberikan motivasi dan semangat kepada siswa agar siswa mampu melaksanakan wawancara dengan percaya diri. Dengan meningkatnya keterampilan berwawancara, guru sebaiknya menggunakan model pembelajaran Think, Pair, Share pada pembelajaran bahasa Indonesia lain yang membutuhkan aktivitas dan kreativitas siswa. Siswa yang belum memenuhi ketuntasan minimal keterampilan berwawancara lebih baik ditindaklanjuti dengan memberikan bimbingan di luar jam belajar sekolah.

\section{DAFTAR RUJUKAN}

Bamiro, A. O. (2015). Effects of Guided Discovery and Think Pair Share Strategies on Secondary School Students' Achievement. SAGE Open, 5(1). https://doi.org/10.1177/2158244014564754

Deremisi, C., \& Düzenli, H. (2017). Formative Value of an Active Learning Strategy: Technology Based Think-Pair-Share in an EFL Writing Classroom. World Journal of Education, 7(6), 63-74. https://doi.org/10.5430/wje.v7n6p63

Erawan, D. G. B. (2014). Penggunaan Metode Sosiodrama untuk Meningkatkan Kemampuan Berwawancara dengan Berbagai Kalangan pada Siswa Kelas VIII SMP Mutiara Singaraja. Santiaji Pendidikan, 4(1).

Kusuma, F. A. M. (2012). Implementasi Model Pembelajaran Think Pair Share untuk Meningkatkan Aktivitas Siswa. Jurnal Pendidikan Akutansi Indonesia, 10(2), 43-63.

Miles, M. B \& Huberman, A. M. (2010). Analisis Data Kualitatif Buku Sumber tentang Metode-Metode Baru. Jakarta: UI Press. Mudini dan Salamat. (2009). Pembelajaran Berbicara. Jakarta: Departemen Pendidikan Nasional.

Mudiono, A. (2010). Pengembangan Bahan Pembelajaran Bahasa Indonesia Sekolah Dasar. Malang: Fakultas Ilmu Pendidikan Universitas Negeri Malang. 
Mulyasa. (2013). Praktik Penelitian Tindakan Kelas. Bandung: Remaja Rosdakarya.

Raba, A. (2017). The Influence of Think Pair Share on Improving Student Oral Communication Skills in Classroom. Creative Education, 8(1), 12.

Rosita, I \& Leonard, L. (2015). Meningkatkan Kerjasama Siswa melalui Pembelajaran Kooperatif Tipe Think Pair Share. Jurnal Ilmiah Pendidikan MIPA, 3(1), 43.

Sampsel. (2013). Finding the Effect of Think Pair Share on Student Confidence and Participation. BGSU.

Sugiarto, D. \& Sumarsono, P. (2014). The Implementation of Think Pair Share Model to Improve Student Ability in Reading Narative. International Jurnal of English and Education, 3(3), 206-2015.

Tarigan, H. G. (2008). Berbicara sebagai Suatu Keterampilan Berbahasa. Bandung: Aksara Bandung.

Tembang, Y., Sulthon., \& Suharjo. (2017). Peningkatan Motivasi dan Hasil Belajar melalui Model Pembelajaran Think, Pair, Share Berbantuan Media Gambar di Sekolah Dasar. Jurnal Pendidikan,Teori, Penelitian, dan Pengembangan, 2(6), 812817.

Usman, A. H. (2015). Using Think Pair Share Strategi to Improve Student Speaking Ability at STAIN Ternate. Journal of Education and Practice, 6(10), 37-45.

Widyatirni. (2013). Metode Bermain Peran Dalam Keterampilan Berbicara Siswa Kelas V SDN Peneleh Surabaya. Jurnal Penelitian Pendidikan Guru Sekolah Dasar, 1(1).

Williams, G. (2011). The Simplicity of Think Pair Share. Washington DC: The Cronide of Hinger Education. 